\title{
Insuficiência aórtica e displasia de tricúspide em um potro de 10 meses: relato de caso
}

Karoline Koether, Simone Biagio Chiacchio; Alexandre Secorun Borges, Maria Lúcia Gomes Lourenço, Juliana Bornhausen Araújo, Mayra de Castro Ferreira Lima, Amanda Sarita Cruz Aleixo, Juliana Almeida Nogueira da Gama

Faculdade de Medicina Veterinária e Zootecnia, Universidade Estadual Paulista (UNESP), Botucatu, SP, Brasil

*Autor correspondente

e-mail: chiacchios@fmvz.unesp.br

\section{Resumo}

O coração é um excelente órgão para se realizar imagens ultrassonográficas, uma vez que o sangue dentro das câmaras cardíacas é relativamente anecóico, o que favorece o delineamento das válvulas ecogênicas e paredes da câmara. Sons cardíacos anormais em animais jovens são consistentes com cardiopatias congênitas. Defeito de septo ventricular é a cardiopatia congênita mais comum em equinos, sendo que anomalias valvulares são raras e ocorrem principalmente nas valvas semilunares aórticas e nas válvulas atrioventriculares (displasia de mitral e tricúspide). Assim, o presente relato teve como objetivo descrever o caso de um animal da espécie equina, portador de insuficiência aórtica e displasia de tricúspide. Um potro, 10 meses de idade, $150 \mathrm{~kg}$, Mangalarga, foi atendido com queixa principal de emagrecimento progressivo, hiporexia e cansaço fácil. Ao exame clínico, o animal apresentava mucosas róseas, desidratação $5 \%$, temperatura retal de 38,4\% $\mathrm{C}$, taquicardia ( 94 batimentos por minuto) e frequência respiratória de 24 movimentos por minuto. À auscultação cardíaca, verificou-se sopro holossistólico (grau III/VI), com ponto de maior intensidade no $4^{\circ}$ espaço intercostal esquerdo (foco aórtico) e sopro grau IV/VI em tricúspide. À auscultação pulmonar, detectou-se ruído traqueobrônquico e bronco-bronquiolar. Foi observada presença de edema em prepúcio. As fezes apresentavam-se ressecadas e recobertas de muco. Foram solicitados exames complementares, sendo que o ecodopplercardiograma revelou espessamento das cúspides das valvas atrioventriculares, sendo a cúspide da parede livre da valva tricúspide levemente displásica. À avaliação da valva semilunar esquerda (aórtica), observou-se aspecto e movimentação anormal, e ao estudo Doppler, constatou-se insuficiência de grau importante. De acordo com os achados ecodopplercardiográficos, o paciente era portador de cardiopatias congênitas compatíveis com insuficiência aórtica e displasia de tricúspide. $\mathrm{O}$ paciente encontrava-se no estágio $\mathrm{C}$ da ICC e foi instituída terapia com maleato de enalapril $0,5 \mathrm{mg} / \mathrm{kg}$, VO, BID e furosemida $1 \mathrm{mg} / \mathrm{kg}$, IM, BID. Desta forma, conclui-se que sopros cardíacos devem ser 
investigados e avaliados com exames específicos em equinos, pois o impacto de qualquer anormalidade cardiovascular no desempenho presente e futuro desses animais pode ocasionar perdas econômicas, sendo as cardiopatias congênitas nem sempre diagnosticadas, uma vez que são consideradas raras na espécie.

Palavras-chave: Equino. Cardiopatias. Sopro. Ecodopplercardiograma. Aorta. 